\title{
Long-term kidney function in children with Wilms tumour and constitutional WT1 pathogenic variant
}

\author{
Maria Pia Falcone ${ }^{1,2} \cdot$ Kathryn Pritchard-Jones $^{1} \cdot$ Jesper Brok $^{1,3} \cdot$ William Mifsud $^{1} \cdot$ Richard D. Williams $^{1}$. \\ Kayo Nakata ${ }^{1} \cdot$ Suzanne Tugnait ${ }^{1} \cdot$ Reem Al-Saadi $^{1,4} \cdot$ Lucy Side $^{5}$ • John Anderson ${ }^{1}$ - Catriona Duncan ${ }^{1}$. \\ Stephen D. Marks ${ }^{1,6}$. Detlef Bockenhauer ${ }^{6,7} \cdot$ Tanzina Chowdhury $^{1}$ (it)
}

Received: 5 November 2018 / Revised: 25 February 2021 / Accepted: 5 May 2021 / Published online: 4 October 2021

(C) The Author(s) 2021

\begin{abstract}
Background Wilms tumour (WT) survivors, especially patients with associated syndromes or genitourinary anomalies due to constitutional WT1 pathogenic variant, have increased risk of kidney failure. We describe the long-term kidney function in children with WT and WT1 pathogenic variant to inform the surgical strategy and oncological management of such complex children.

Methods Retrospective analysis of patients with WT and constitutional WT1 pathogenic variant treated at a single centre between 1993 and 2016, reviewing genotype, phenotype, tumour histology, laterality, treatment, patient survival, and kidney outcome.

Results We identified 25 patients (60\% male, median age at diagnosis 14 months, range 4-74 months) with WT1 deletion (4), missense (2), nonsense (8), frameshift (7), or splice site (4) pathogenic variant. Thirteen (52\%) had bilateral disease, $3(12 \%)$ had WT-aniridia, 1 had incomplete Denys-Drash syndrome, 11 (44\%) had genitourinary malformation, and $10(40 \%)$ had no phenotypic anomalies.

Patient survival was $100 \%$ and 3 patients were in remission after relapse at median follow-up of 9 years. Seven patients (28\%) commenced chronic dialysis of which 3 were after bilateral nephrectomies. The overall kidney survival for this cohort as mean time to start of dialysis was 13.38 years (95\% CI: 10.3-16.4), where 7 patients experienced kidney failure at a median of 5.6 years. All of these 7 patients were subsequently transplanted. In addition, 2 patients have stage III and stage IV chronic kidney disease and 12 patients have albuminuria and/or treatment with ACE inhibitors. Four patients ( 3 frameshift; 1 WT1 deletion) had normal blood pressure and kidney function without proteinuria at follow-up from 1.5 to 12 years.

Conclusions Despite the known high risk of kidney disease in patients with WT and constitutional WT1 pathogenic variant, nearly two-thirds of patients had sustained native kidney function, suggesting that nephron-sparing surgery (NSS) should be attempted when possible without compromising oncological risk. Larger international studies are needed for accurate assessment of WTIgenotype-kidney function phenotype correlation.
\end{abstract}

Keywords Wilms tumour $\cdot$ WT1 pathogenic variant $\cdot$ Kidney function

\section{Introduction}

Wilms tumour (WT) or nephroblastoma is an embryonal tumour and the most common kidney tumour in childhood. It

Tanzina Chowdhury

Tanzina.Chowdhury@gosh.nhs.uk

1 Department of Paediatric Oncology Great Ormond Street Hospital, UCL Institute of Child Health, NIHR Great Ormond Street Hospital Biomedical Research Centre, London, UK

2 Paediatric Residency Program, University of Foggia, Foggia, Italy

3 Dept. of Paediatric Haematology and Oncology, Rigshospitalet, Copenhagen University Hospital, Copenhagen, Denmark affects one in 10,000 children and accounts for about $5 \%$ of all childhood cancers [1-3]. Survival of WT has improved significantly and the cure rate is approximately $90 \%$ when adhering to optimal treatment [4]. However, the treatment and

4 Dept. of Histopathology, Great Ormond Street Hospital for Children NHS Foundation Trust, London, UK

5 Dept. of Clinical Genetics, Great Ormond Street Hospital for Children NHS Foundation Trust, London, UK

6 Dept. of Paediatric Nephrology, Great Ormond Street Hospital for Children NHS Foundation Trust, London, UK

7 UCL Department of Renal Medicine, London, UK 
the genetic conditions occasionally associated with the disease result in additional health challenges among survivors. Kidney failure in particular is a concerning outcome. In the National Wilms Tumor Study (NWTS), the 20-year cumulative overall incidence of kidney failure was $1.3 \%$ for unilateral WT patients and $15 \%$ for bilateral WT [5].

Significantly higher rates of kidney failure were found among patients with WAGR syndrome (WAGR), Denys-Drash syndrome (DDS), and those with associated male genitourinary (GU) anomalies, all related to constitutional WT1 pathogenic variants $[6,7]$. The rate of deterioration of kidney function varies according to the syndrome, with a much earlier onset of kidney failure described in children with DDS (due to intragenic WT1 pathogenic variants) than in those with a complete deletion of one allele of WT1, as in WAGR syndrome [8]. Frasier syndrome, due to $W T 1$ splicing pathogenic variant, has an intermediate rate of decline in kidney function and a much lower risk of WT [9, 10].

It has been reported that $74 \%$ of Denys-Drash patients, $36 \%$ of WAGR patients, and $7 \%$ of hypospadias or cryptorchidism patients had kidney failure at 20 years of follow-up, compared with only about $1 \%$ of non-syndromic children [5].

The phenotypic spectrum associated with constitutional WT1 pathogenic variant is broad. We await prospective studies to determine more accurately the proportion of patients with WTI pathogenic variant who have unilateral WT without associated GU abnormalities. Two previous studies that sequenced the WT1 gene in non-syndromic children with WT found a very low percentage in the absence of at least bilateral disease $[6,11]$. Therefore, relying on phenotype alone to identify individuals with WT who have constitutional WT1 pathogenic variant may be challenging. Factors that may indicate that an individual with normal phenotype is carrying a constitutional WT1 pathogenic variant are as follows: bilateral disease, diagnosis with WT before the age of 1 year, stromal-predominant histology, and intralobar nephrogenic rests (ILNR) [12-14]. Among such patients, with incomplete clinical features of WT1-related syndromes and in whom WT1 missense or stop pathogenic variants are found, the impact of pathogenic variant type on the expected rate of deterioration of kidney function is currently unclear.

A well-known oncological dilemma is the balanced decision between either complete resection of WT to optimize tumour control, or the performing of nephron-sparing surgery (NSS) for syndromic patients to preserve kidney function. When feasible, it is now standard practice that NSS should be attempted at the time of WT resection in children with bilateral tumours, syndromic features, and those with other predisposing factors. Due to the higher risk of relapse in the contralateral kidney, the maximum possible parenchymal reserve capacity should be preserved, in order to prevent or postpone kidney failure [14]. Prior knowledge of the presence of a constitutional WT1 pathogenic variant and its subtype may have important implications in predicting the risk and rate of deteriorating function of the remaining nephrons $[15,16]$.
The aim of our study is to describe the long-term kidney function of children with WT and constitutional WT1 pathogenic variant in relation to their phenotype, genotype, and treatment received. These findings could guide clinical management in the future of children with similar clinical and genetic features, through a greater understanding of the longevity of their clinically useful kidney function.

\section{Methods}

\section{Patients}

We identified retrospectively from hospital records and the oncology departmental database of patients with kidney tumours, cases of patients with co-existing WT and constitutional WT1 pathogenic variant who received treatment between 1993 and 2016 at Great Ormond Street Hospital for Children NHS Foundation Trust (GOSH), UK. WT1 pathogenic variant testing was done at different points for each patient as directed by the clinical presentation. This could be at diagnosis, during treatment, or at follow-up particularly in the older cases. Patients with WAGR and DDS were included. WAGR patients were defined as those with the full complement of WT, aniridia (AN), GU malformations, and intellectual disability (MIM\#194072). DDS patients were defined as having WT, nephropathy presenting as persistent proteinuria or overt nephrotic syndrome, and GU anomalies (MIM\#194080) [17, 18]. WT patients with only some of these phenotype anomalies were categorized by their specific features (AN, diffuse mesangial sclerosis (DMS), and GU malformations).

We collected data on patient and tumour demographics which comprised patient gender, age at diagnosis, and phenotypic anomalies; tumour histology, laterality, multifocality, tumour volume at diagnosis and after pre-operative treatment; and treatment details of chemotherapy, type of surgery, and radiation received.

All patients had pre-operative chemotherapy and tumour histological subtype was according to the revised SIOP classification [19]. For tumours classified initially according to other protocols, a second pathological review was performed by an expert pediatric pathologist (WM) for the purposes of this study. Tumours were also categorized according to the presence or absence of rhabdomyoblastic differentiation and intralobar and perilobar nephrogenic rests (ILNR and PLNR, respectively).

\section{Pathogenic variant detection}

All WT1 pathogenic variants and deletions were identified from peripheral blood lymphocytes by an NHS genetic diagnostic service, using Sanger sequencing, MLPA (multiplex ligation-dependent probe amplification), and, in older cases, FISH (fluorescent in situ hybridization). Non-syndromic 
patients with WT in our service were selected for constitutional WT1 pathogenic variant testing at the discretion of the treating clinician based on previously published criteria suggesting a higher risk of such pathogenic variant [13] or when they had some features of DDS in the absence of urogenital malformation (persistent hypertension or proteinuria).

Patients were classified according to the type of WT1 pathogenic variant: deletion, missense, nonsense, frameshift, and splice site.

\section{Kidney function}

We assessed the following data at diagnosis and at the last follow-up: kidney function with serum creatinine and estimated glomerular filtration rate (eGFR), urine albumin to creatinine ratio, blood pressure, and use of anti-hypertensiveand/ oranti-proteinuric medications.

The GFR was estimated using the revised Schwartz formula: eGFR $\left(\mathrm{ml} / \mathrm{min} / 1.73 \mathrm{~m}^{2}\right)=\mathrm{k} \times$ height $(\mathrm{cm}) /$ serum creatinine $(\mu \mathrm{mol} / \mathrm{l})$ with a $\mathrm{k}$ value of $33[20,21]$. If the height of the patient was missing, it was estimated from the percentile growth chart of the patient. The eGFR was used to stage the kidney function of the patients according to standard criteria [22]. Albuminuria was defined as a urine albumin to creatinine ratio above the age-adjusted normal range.

WT patients were categorized as having kidney failure if they received chronic kidney replacement therapy with dialysis or transplantation. The malignancy was regarded as the cause of kidney failure if the patient needed surgical removal of all the kidney tissue as a result of widespread/progressive bilateral WT or a relapse in the solitary kidney that required nephrectomy.

\section{Statistical analysis}

Numerical variables were summarized as medians and standard deviation as the data followed a non-parametric distribution. Categorical and ordinal variables were described as relative frequencies. Medians and frequencies were compared using Mann-Whitney's U test and the Kruskal-Wallis test respectively. All tests were two-sided and a $\mathrm{p}$ value $=0.05$ was considered significant. All statistical analysis was performed using SPSSC (version 24.0; SPSS Inc. Chicago, IL).

\section{Results}

\section{Patient characteristics}

We identified 26 patients with WT and constitutional WT1 pathogenic variant and one patient with a complete phenotype of WAGR syndrome who had no documented analysis of WT1 pathogenic variant but is assumed to have a constitutional deletion (Table 1). We excluded two patients, one with less than 6 months of follow-up from the date of diagnosis and one without available data on kidney function. Fifteen were male and median age at diagnosis of the whole cohort was 14 months (range 4-74 months).

Fifteen (60\%) patients (13 males, 2 females) had associated phenotypic anomalies: WAGR $(\mathrm{n}=2 ; 8 \%)$; AN $(\mathrm{n}=1 ; 4 \%)$; incomplete DDS $(\mathrm{n}=1 ; 4 \%)$; GU malformations $(\mathrm{n}=11 ; 44 \%)$ including cryptorchidism, hypospadias, and micropenis. In the remaining $10(40 \%)$ patients, no phenotypic anomalies were found. In particular, no GU abnormalities were reported in any female patients (Table 1). One unusual male patient carried the splice site pathogenic variant associated with Frasier syndrome that prevents formation of the +KTS isoform of WT1 but lacked any GU malformation. He presented at an older age with WT (74 months) and had albuminuria (albumin to creatinine ratio 140 $\mathrm{mg} / \mathrm{mmol}$ ) but normal creatinine and GFR. His kidney function deteriorated slowly over the subsequent 7 years at which time transplant was recommended. Another female patient had unilateral WT without other abnormal clinical features but presented with nephrotic syndrome 3 years after her WT nephrectomy. She developed stage 5 chronic kidney disease 5 years later, underwent second nephrectomy with evidence of nephroblastomatosis, and received a transplant 11 years later.

\section{WT1 constitutional pathogenic variants}

The patients were subdivided according to type of WT1 pathogenic variant into the following subgroups (Table 2): large WAGR deletions encompassing the $11 \mathrm{p} 13$ region and entire WT1 gene (4 patients; note one deletion did not extend into the PAX6 gene); missense ( 2 patients); nonsense ( 8 patients); frameshift (7 patients); and splice site pathogenic variant (4 patients). The patient with full WAGR phenotype but no genetic testing is assumed to carry deletion of the $11 \mathrm{p} 13$ region.

The median age at WT diagnosis according to pathogenic variant type was 9 months (3.8-62.9) frameshift, 13 months (7.5-74.3) splice site, 14 months (5.5-29.6) nonsense, 15 months (12.6-17.6) missense, and 24 months (14.0-47.5) deletions for their respective pathogenic variant types.

We observed variation in the frequency of bilateral tumours by pathogenic variant type, $7 / 8$ patients carrying nonsense pathogenic variants compared with frameshift (3/7), splice site $(2 / 4)$, deletions $(1 / 4)$, and missense $(0 / 2)$, but this did not reach statistical significance ( $\mathrm{p}=0.192$; Tables 1 and 2). Both missense variants affect functionally important residues in zinc finger 3, base-contacting residue Arg394, and zinc coordination residue His405.

\section{Tumour features}

\section{Tumour stage}

Most tumours $(\mathrm{n}=22 / 36 ; 61 \%)$ were abdominal stage 1 . Three patients $(12 \%)$ had metastases at diagnosis (two with 


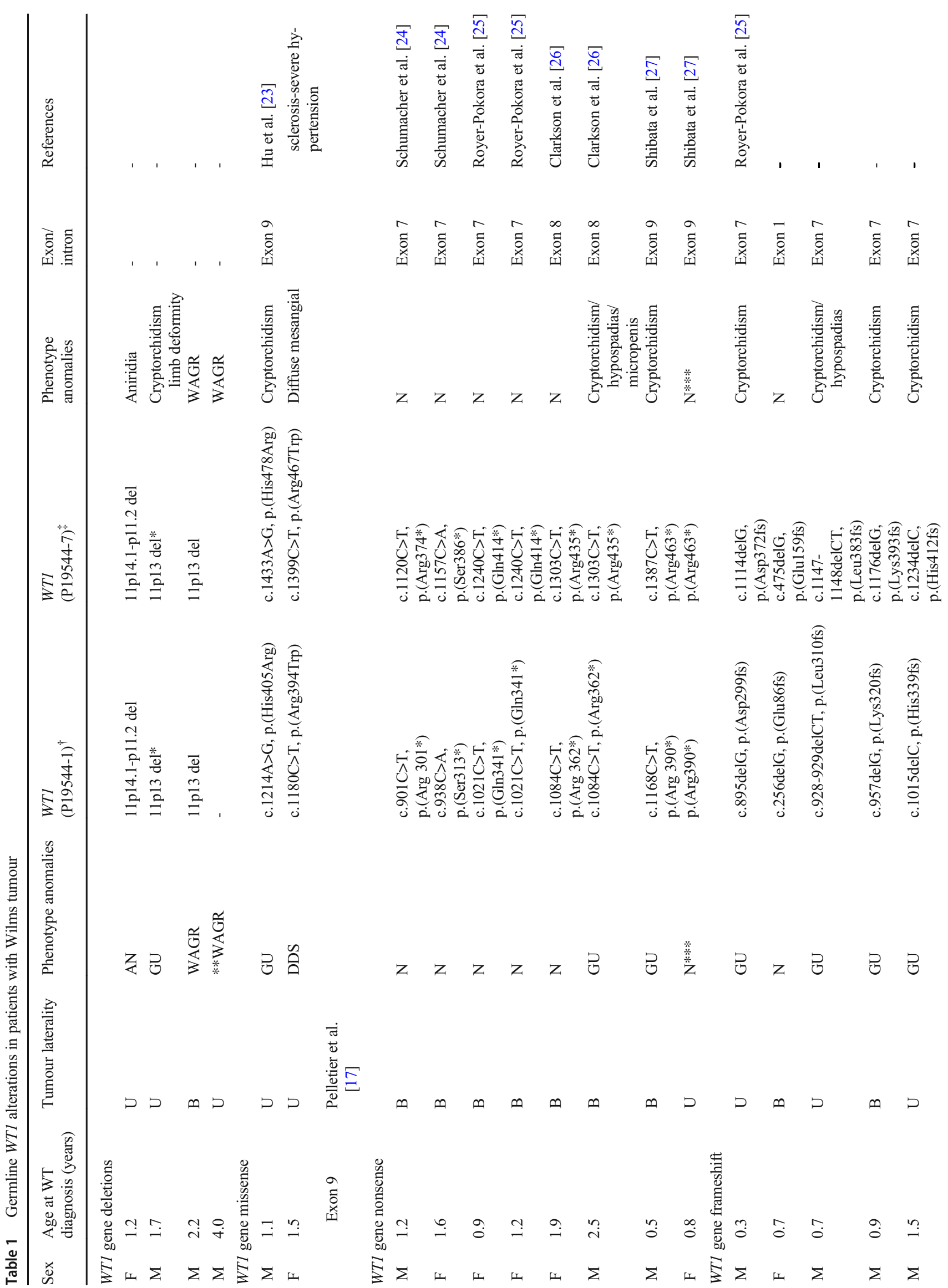




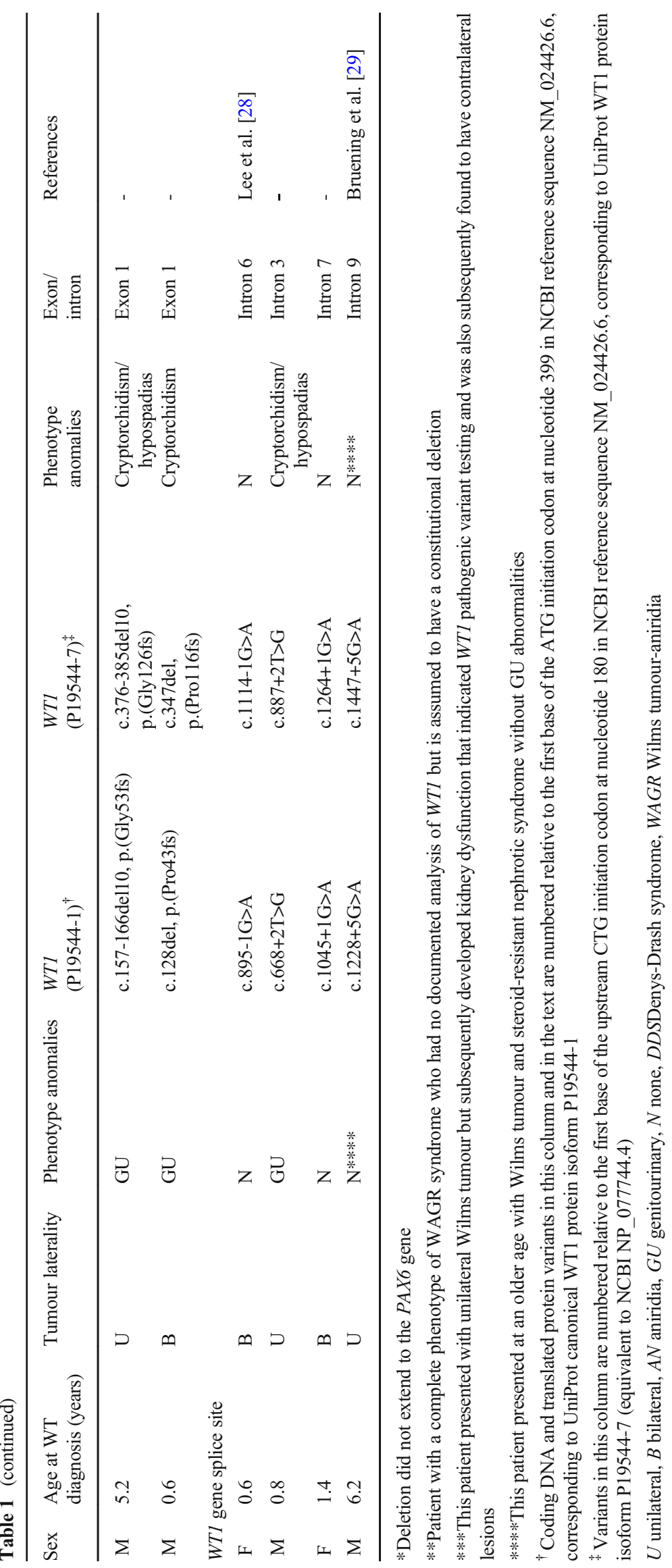


Table 2 Clinical features of the patients with WT and WT1 pathogenic variant

\begin{tabular}{|c|c|c|c|c|c|c|}
\hline \multirow[t]{2}{*}{ Characteristic } & \multirow[t]{2}{*}{ All patients } & \multicolumn{5}{|c|}{ Type of WT1 mutation } \\
\hline & & Deletion & Missense & Nonsense & Frameshift & Splice site \\
\hline Patient (number) & 25 & 4 & 2 & 8 & 7 & 4 \\
\hline Male & $15(60 \%)$ & 3 & 1 & 3 & 6 & 2 \\
\hline Female & $10(40 \%)$ & 1 & 1 & 5 & 1 & 2 \\
\hline Median age at diagnosis (months)/range & 14 & $\begin{array}{l}24 \\
(14.0-47.5)\end{array}$ & $\begin{array}{l}15 \\
(12.6-17.6)\end{array}$ & $\begin{array}{l}14 \\
(5.5-29.6)\end{array}$ & $\begin{array}{l}9 \\
(3.8-62.9)\end{array}$ & $\begin{array}{l}13 \\
(7.5-74.3)\end{array}$ \\
\hline Median follow-up duration (years)/range & 9 & $\begin{array}{l}6 \\
(1.0-9.9)\end{array}$ & $\begin{array}{l}6 \\
(4.2-7.5)\end{array}$ & $\begin{array}{l}14 \\
(1.2-21.9)\end{array}$ & $\begin{array}{l}9 \\
(1.5-12)\end{array}$ & $\begin{array}{l}11 \\
(6.7-19.4)\end{array}$ \\
\hline \multicolumn{7}{|l|}{ Phenotype, n (\%) } \\
\hline WAGR & $2(8 \%)$ & 2 & - & - & - & - \\
\hline Aniridia & $1(4 \%)$ & 1 & - & - & - & - \\
\hline DDS & $1(4 \%)$ & - & 1 & - & - & - \\
\hline GU malformation & $11(44 \%)$ & 1 & 1 & 2 & 6 & 1 \\
\hline No phenotype alteration & $10(40 \%)$ & - & - & 6 & 1 & 3 \\
\hline Bilateral tumour, n (\%) & $13(52 \%)$ & 1 & - & 7 & 3 & 2 \\
\hline \multicolumn{7}{|l|}{ Tumour histology, n (\%)* } \\
\hline Total no. of tumours & 36 & & & & & \\
\hline Mixed type & $13(36 \%)$ & 2 & 2 & 5 & 3 & 1 \\
\hline Stromal type & $17(47 \%)$ & 3 & - & 6 & 5 & 3 \\
\hline Regressive type & $2(6 \%)$ & - & - & - & 1 & 1 \\
\hline Blastemal type & $1(3 \%)$ & - & - & - & - & 1 \\
\hline Nephrogenic rest only & $3(8 \%)$ & - & - & 2 & 1 & - \\
\hline Nephrogenic rest, n (\%) & $25(70 \%)$ & 5 & 2 & 9 & 4 & 5 \\
\hline ILNR, n (\%) & $19(76 \%)$ & 4 & 1 & 8 & 3 & 3 \\
\hline PLNR, n (\%) & $6(17 \%)$ & - & 2 & 1 & 1 & 2 \\
\hline $\begin{array}{l}\text { Rhabdomyoblastic } \\
\text { differentiation, } \mathrm{n}(\%)\end{array}$ & $22(61 \%)$ & 1 & - & 9 & 8 & 4 \\
\hline Relapse, n (\%) & $3(12 \%)$ & - & - & 1 & 1 & 1 \\
\hline Haemodialysis, n (\%) & $7(28 \%)$ & - & 1 & 4 & 1 & 1 \\
\hline Kidney transplant, $\mathrm{n}(\%)$ & $7(28 \%)$ & - & 1 & 4 & 1 & 1 \\
\hline $\mathrm{eGFR}<60 \mathrm{ml} / \mathrm{min} / 1.73 \mathrm{~m}^{2}$ at last follow-up & $2(8 \%)$ & - & - & 1 & - & 1 \\
\hline Albuminuria & $9(36 \%)$ & 2 & 1 & 2 & 2 & 2 \\
\hline On anti-hypertensive drugs & $10(40 \%)$ & 3 & 1 & 2 & 3 & 1 \\
\hline
\end{tabular}

*Histological subtypes refer to 24 patients, 12 with bilateral disease (36 tumours)

lung metastases and one with liver metastases). Bilateral WT was observed in $13(52 \%)$ patients, more frequently in females $(7 / 10)$, than in males $(6 / 15 ; p=0.216)$.

\section{Tumour histology}

Tumour histology was available for review in 24 patients, including 12 patients with bilateral disease (total 36 tumours). According to the SIOP 2001 classification, 23 (92\%) patients had tumours that were intermediate-risk histology, one patient had high-risk (blastemal-type), and one had WT where the histological classification was unknown. Of 36 tumours where histology was known, $32(88 \%)$ were of intermediate-risk histology, 17 (47\%) of which were stromal-type; 13 (36\%) mixed type; and 2 (6\%) regressive type, and one was of high-risk blastemal-type histology. No patient had low-risk histology or anaplastic tumour. Three tumours (8\%) showed only ILNR.

Rhabdomyoblastic differentiation was seen in 22/36 (61\%) of tumours. In the normal kidney parenchyma adjacent to the tumour, diffuse mesangial sclerosis (DMS) was observed in two patients and nephrogenic rests in 25/36 (69\%) tumours, where 19 tumours had ILNR, six had PLNR, and none had both.

Tumour volume was available for 19 patients according to imaging (magnetic resonance imaging, computed tomography, 
or ultrasound). Of these, five had multifocal disease. After preoperative chemotherapy, 11 (58\%) had tumour volume reduction and one had stable disease. Seven (37\%) patients had increased tumour volume all of whom showed rhabdomyoblastic differentiation and $5 / 7$ were of stromal subtype.

\section{Treatment}

All patients had pre-operative chemotherapy with 18 patients treated according to the SIOP 2001 protocol and seven according to similar previous national protocols. Among the 13 patients with bilateral tumours, two underwent up-front bilateral nephrectomies, three had bilateral NSS, and eight unilateral nephrectomy with contralateral NSS. Of the 12 patients with unilateral tumour, one had bilateral nephrectomies due to kidney failure, two underwent unilateral NSS, and nine had unilateral nephrectomy of whom two subsequently had metachronous relapse treated by contralateral nephrectomy in one case and contralateral NSS in the other. Ultimately, 21/25 (84\%) patients retained some functioning kidney tissue.

Five $(20 \%)$ patients received radiotherapy, with four patients receiving unilateral flank radiotherapy due to abdominal stage III WT, and one patient whole lung radiotherapy due to pulmonary metastases.

\section{Clinical outcome}

Patient overall survival was $100 \%$, with three patients in remission after disease relapse, and kidney survival was $72 \%$ at median follow-up of 9 years. Seven patients $(28 \%)$ commenced chronic dialysis of which three were after bilateral nephrectomies (one patient had subsequent contralateral nephrectomy due to relapse). The median time between the diagnosis and the start of haemodialysis was $5.6(0-16)$ years (Table 3 ). Kidney survival (time from diagnosis of WT to start dialysis) is shown by the Kaplan-Meier graph in Fig. 1. The overall kidney survival for this cohort as mean time to start of dialysis was 13.38 years (95\% CI: 10.3-16.4), where 7 patients reached kidney failure at a median of 5.6 years. All of these seven patients were subsequently transplanted. Twelve patients had albuminuria and/or were prescribed ACE inhibitors. Two of these patients had albuminuria only, while among ten patients who were commenced on medication, six were being treated for hypertension and four were receiving anti-proteinuric medication. Two patients had stage III and stage IV chronic kidney disease (CKD). Four patients (3 frameshift; 1 WT1 deletion) had normal blood pressure and kidney function without proteinuria at follow-up from 1.5 to 12 years (Table 4).

In each individual patient, we assessed the frequency of the following clinical/histologic factors suggestive of potential WTI pathogenic variant: age at diagnosis $<12$ months, bilateral WT, GU malformation, ILNR, DMS, rhabdomyoblastic differentiation, albuminuria at diagnosis, and persistent hypertension after nephrectomy (Table 5). Nineteen of 25 patients had at least three or more of these clinical/histologic features, two patients had two characteristic features (GU malformation and ILNR), and the remaining four patients had only one feature, although two of these also had a WT1-associated syndrome.

\section{Discussion}

This detailed study of 25 consecutively diagnosed patients with Wilms tumour and constitutional WT1 pathogenic

Table 3 Patients with WT and WT1 pathogenic variant who required long-term dialysis

\begin{tabular}{|c|c|c|c|c|c|c|c|c|c|c|}
\hline Sex & $\begin{array}{l}\text { Laterality of } \\
\text { tumour }\end{array}$ & $\begin{array}{l}\text { Phenotype } \\
\text { anomalies }\end{array}$ & $\begin{array}{l}\text { WT1 } \\
\text { pathogenic } \\
\text { variant }\end{array}$ & $\begin{array}{l}\text { WT1 } \\
\text { (P19544-7) }\end{array}$ & $\begin{array}{l}\text { Histologic } \\
\text { subtype }\end{array}$ & Surgery & Relapse & $\begin{array}{l}\text { Kidney } \\
\text { transplant }\end{array}$ & $\begin{array}{l}\text { Diagnosis- } \\
\text { dialysis (years) }\end{array}$ & $\begin{array}{l}\text { Follow-up } \\
\text { (years) }\end{array}$ \\
\hline M & B & GU & Nonsense & $\begin{array}{l}\text { c. } 1387 \mathrm{C}>\mathrm{T} \text {, } \\
\text { p. }\left(\operatorname{Arg} 463^{*}\right)\end{array}$ & Stromal/mixed & $\begin{array}{l}\text { UN+ } \\
\text { NSS }\end{array}$ & $\mathrm{N}$ & Yes & 15.9 & 17.5 \\
\hline $\mathrm{F}$ & B & $\mathrm{N}$ & Frameshift & $\begin{array}{l}\text { c. } 475 \text { delG, } \\
\text { p.(Glu159fs) }\end{array}$ & Stromal/mixed & $\mathrm{BN}$ & $\mathrm{N}$ & Yes & 0.3 & 11.6 \\
\hline $\mathrm{F}$ & $\mathrm{U}$ & $\mathrm{N}$ & Nonsense & p. $(\operatorname{Arg} 463 *)$ & Stromal & UN & $\mathrm{N}$ & Yes & 9.5 & 21.9 \\
\hline M & $\mathrm{U}$ & GU & Splice site & c. $887+2 \mathrm{~T}>\mathrm{G}$ & Stromal & $\mathrm{UN}^{*}$ & Yes & Yes & 5.6 & 10.4 \\
\hline $\mathrm{F}$ & $\mathrm{U}$ & DDS & Missense & $\begin{array}{l}\text { c. } 1399 \mathrm{C}>\mathrm{T}, \\
\text { p. }(\operatorname{Arg} 467 \mathrm{Tr}- \\
\text { p) }\end{array}$ & Mixed/DMS & $\mathrm{BN}^{* *}$ & $\mathrm{~N}$ & Yes & 0.1 & 4.2 \\
\hline $\mathrm{F}$ & B & $\mathrm{N}$ & Nonsense & $\begin{array}{l}\text { c. } 1303 \mathrm{C}>\mathrm{T}, \\
\text { p. }\left(\operatorname{Arg} 435^{*}\right)\end{array}$ & - & $\begin{array}{l}\text { UN+ } \\
\quad \text { NSS }\end{array}$ & $\mathrm{N}$ & Yes & 14.5 & 14.9 \\
\hline $\mathrm{F}$ & B & $\mathrm{N}$ & Nonsense & $\begin{array}{l}\text { c. } 1240 \mathrm{C}>\mathrm{T}, \\
\text { p. }\left(\mathrm{G} \ln 414^{*}\right)\end{array}$ & Stromal & $\mathrm{BN}$ & $\mathrm{N}$ & Yes & 0.3 & 3.0 \\
\hline
\end{tabular}

*This patient had unilateral nephrectomy as first-line treatment and subsequent contralateral nephrectomy due to relapse

**Although the patient had a unilateral tumour, he received up-front bilateral nephrectomies due to kidney failure at diagnosis

$U$ unilateral, GU genitourinary, $U N$ unilateral nephrectomy, NSSnephron-sparing surgery 
Fig. 1 Kaplan-Meier graph of renal survival (time from diagnosis of WT to start dialysis). The overall renal survival for this cohort as mean time to start of dialysis was 13.38 years $(95 \% \mathrm{CI}$ : 10.3-16.4), where 7 patients reached kidney failure at a median of 5.6 years. All of the 7 patients were subsequently transplanted

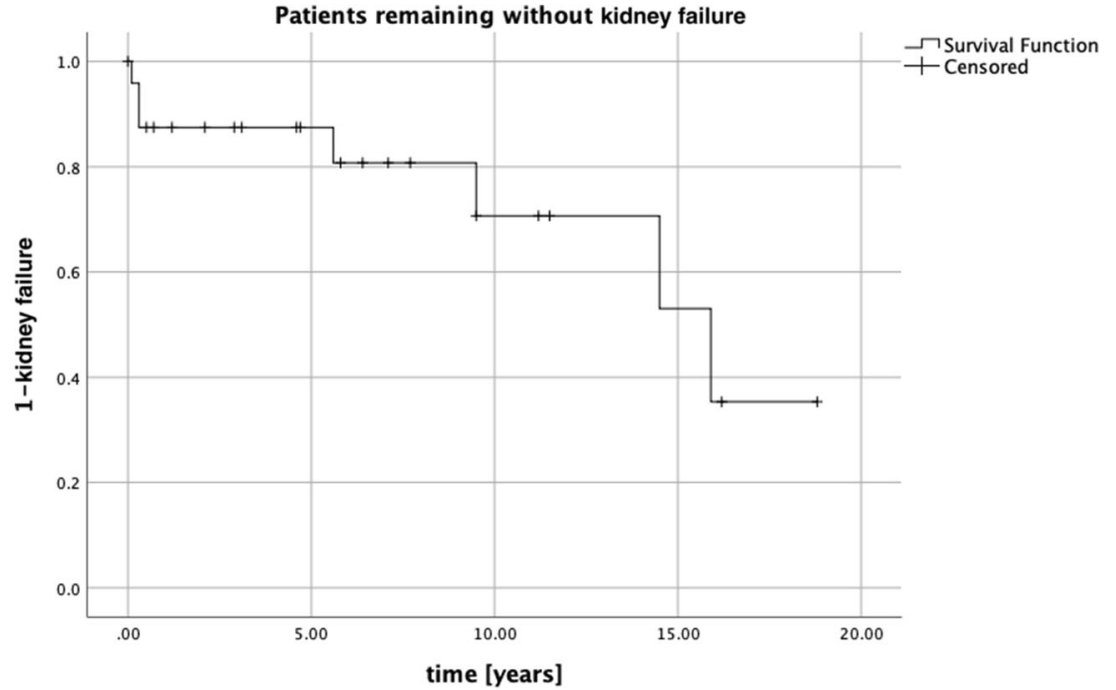

variant presenting to the largest childhood cancer centre in the UK over a 27 -year period describes a clinical approach to recognizing such children and the potential for longevity of kidney function.

Our results confirm the previously described features observed in children with WT who carry a WT1 pathogenic variant $[6,25]$ and emphasize how these can be variably present according to type of WT1 pathogenic variant (Table 2) and by individual patient (Table 5). The small cohort size, due to the rarity of these patients, does not provide sufficient power for formal statistical analysis of WT1genotype-phenotype correlations.

Previous descriptions of WT in children with underlying constitutional WT1 pathogenic variant have emphasized the association with GU malformation [29]. This is in line with the established role of WT1 in normal GU development [30, 31]. Despite this, in our study, $10(40 \%)$ patients had no GU abnormalities, and in particular, no GU malformations were reported in female patients. Among the four patients with large deletions encompassing the entire WT1 gene, one did not have $\mathrm{AN}$ as their deletion did not encompass the PAX6 gene and one female patient had only AN and no GU abnormalities, with four having developmental delay. There was similar incomplete phenotypic manifestation among five patients with genotypes commonly described in DDS $[9,32]$. Only one patient was defined as incomplete DDS due to her clinical features at diagnosis (age 17.6 months): WT, kidney failure caused by DMS and severe hypertension, without GU anomalies.

Our findings emphasize the importance of considering clinical and pathological findings in addition to the presence of syndromic features in assessing the likelihood that an individual patient with WT carries a WT1 pathogenic variant. There have been only two major analyses of the prevalence of constitutional WT1 pathogenic variant in unselected, nonsyndromic patients with WT $[6,11]$. Among 483 patients with WT enrolled in two large clinical trials in the UK and North America, only 14 (2.9\%) had constitutional WT1 pathogenic variant. Six were aged less than 12 months at diagnosis, eight had GU malformation, four had bilateral tumours, and all with available histology had stromal subtype tumours (3/3). A smaller, single-centre study from the Netherlands reported a

Table 4 Patients with WT and WTI pathogenic variant with normal kidney parameters after treatment

\begin{tabular}{|c|c|c|c|c|c|c|c|c|}
\hline Sex & $\begin{array}{l}\text { Laterality of } \\
\text { tumour }\end{array}$ & $\begin{array}{l}\text { Congenital } \\
\text { abnormalities }\end{array}$ & $\begin{array}{l}W T 1 \text { pathogenic } \\
\text { variant }\end{array}$ & $\begin{array}{l}\text { WT1 } \\
(\mathrm{P} 19544-7)\end{array}$ & $\begin{array}{l}\text { Histologic } \\
\text { subtype }\end{array}$ & Surgery & Relapse & $\begin{array}{l}\text { Median follow-up } \\
\text { (years) }\end{array}$ \\
\hline M & $\mathrm{U}$ & GU & Frameshift & $\begin{array}{l}\text { c.1114delG, } \\
\text { p.(Asp372fs) }\end{array}$ & Stromal & UN & $\mathrm{N}$ & 1.5 \\
\hline M & $\mathrm{U}$ & GU & Frameshift & $\begin{array}{l}\text { c.1147- } \\
\text { 1148delCT, } \\
\text { p.(Leu383fs) }\end{array}$ & Mixed & UN & $\mathrm{Y}$ & 12 \\
\hline $\mathrm{F}$ & $\mathrm{U}$ & AN & Deletions & $\begin{array}{l}\text { 11p14.1-p11.2 } \\
\text { del }\end{array}$ & Mixed & NSS & $\mathrm{N}$ & 3.3 \\
\hline M & $\mathrm{U}$ & GU & Frameshift & $\begin{array}{l}\text { c.376-385del10, } \\
\text { p.(Gly126fs) }\end{array}$ & Regressive & UN & $\mathrm{N}$ & 11 \\
\hline
\end{tabular}

$U$ unilateral, $G U$ genitourinary, $U N$ unilateral nephrectomy, NSSnephron-sparing surgery 
Table 5 Prevalence of clinical and histologic factors associated with constitutional WT1 pathogenic variant

Features associated with constitutional WT1 pathogenic variant

\begin{tabular}{|c|c|c|c|c|c|c|c|c|}
\hline $\begin{array}{l}\text { Age at } \\
\text { diagnosis } \\
<12 \mathrm{~m}\end{array}$ & $\begin{array}{l}\text { WTl-associated } \\
\text { phenotype (WAGR, AN, } \\
\text { GU, nephropathy) }\end{array}$ & $\begin{array}{l}\text { Bilateral } \\
\text { tumour }\end{array}$ & ILNR & $\begin{array}{l}\text { Rhabdomyoblastic } \\
\text { differentiation }\end{array}$ & $\begin{array}{l}\text { Diffuse } \\
\text { mesangial } \\
\text { sclerosis }\end{array}$ & $\begin{array}{l}\text { Albuminuria } \\
\text { at diagnosis }\end{array}$ & $\begin{array}{l}\text { Post- } \\
\text { nephrectomy } \\
\text { persistent } \\
\text { hypertension }\end{array}$ & $\begin{array}{l}\text { No. of } \\
\text { features } \\
\text { per patient }\end{array}$ \\
\hline
\end{tabular}

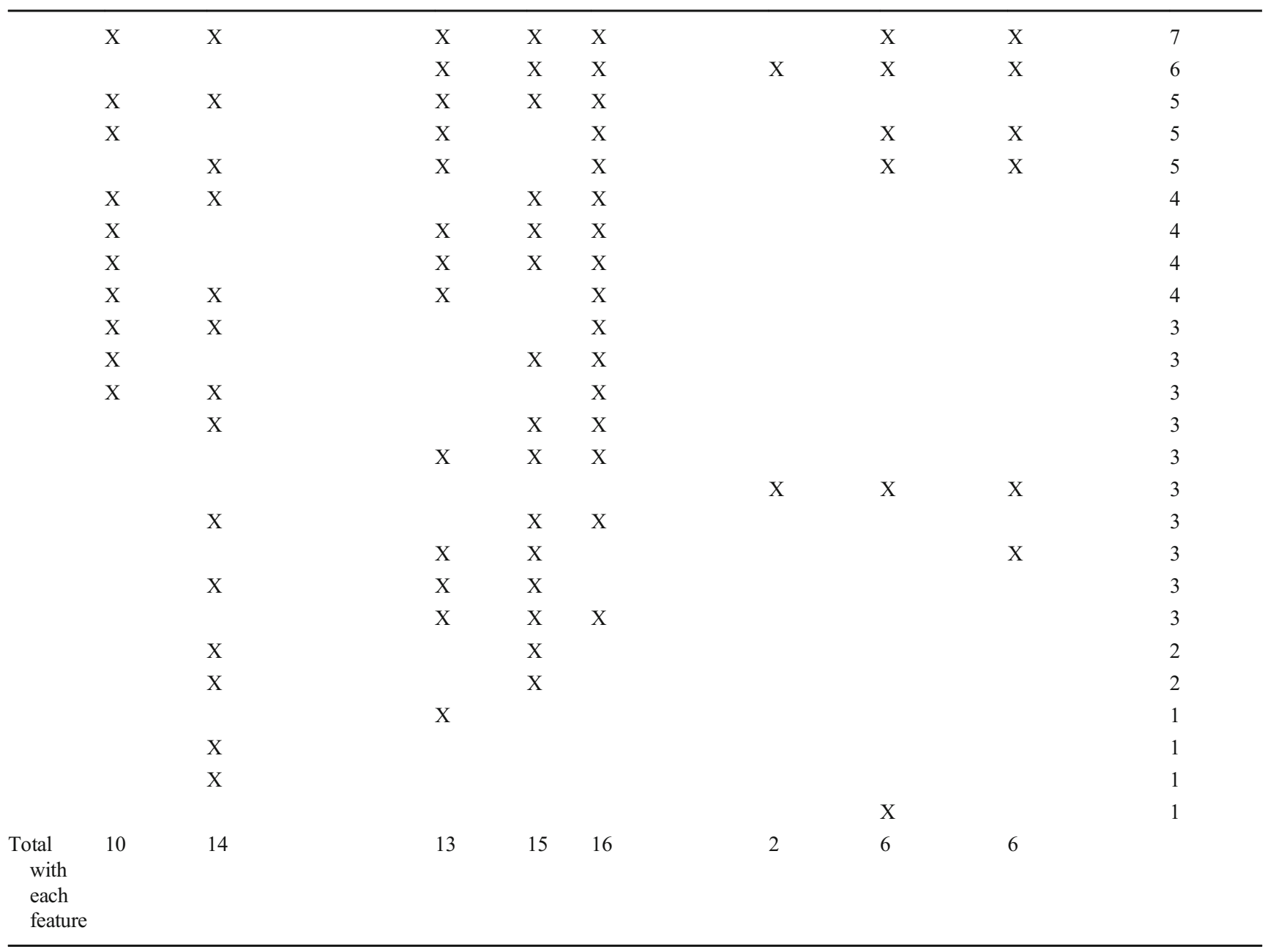

frequency of constitutional WT1 pathogenic variant of $7 \%$ (7/97) in non-syndromic WT survivors attending a follow-up clinic [33]. Among these 7 patients, three were under 1 year of age at diagnosis, three had bilateral tumours, 4 of 5 males had GU malformation (cryptorchidism), and 6 of 7 tumours were stromal subtype.

Early identification of underlying WT1 pathogenic variant in a child with Wilms tumour has potential value in planning the surgical approach to nephron-sparing in relation to the anticipated decline in kidney function. Despite the expected high frequency of kidney failure in patients carrying WT1 pathogenic variants, to date, only seven (out of 25) patients required chronic dialysis. Of these, three had bilateral nephrectomies performed at an early stage, two for non- responsive bilateral disease and one for unilateral WT and kidney failure due to DMS. One patient had a metachronous relapse 5 years from diagnosis and required complete nephrectomy for tumour control. Of the other three patients, two had bilateral WT and underwent unilateral nephrectomy with contralateral NSS and one patient with unilateral WT received unilateral nephrectomy. The median time between the diagnosis and the start of haemodialysis was $5.56(0.3-15.9)$ years.

We investigated whether a difference can be observed between the different WT1 pathogenic variant subgroups for the rate of deterioration of kidney function at last follow-up. We observed that in the nonsense pathogenic variant subgroup $(8$ patients), four patients required chronic dialysis (due to CKD in three patients and due to tumour resection in one patient), 
one developed stage IV CKD (eGFR $21 \mathrm{ml} / \mathrm{min} / 1.73 \mathrm{~m}^{2}$ ), and the other three patients presented albuminuria or were on antiproteinuric medication. However, this higher rate of kidney function deterioration could also be biased due to the longer follow-up (14 years) reported in this subgroup. Only four patients, three with frameshift pathogenic variants and one with WT1 deletion, had completely normal kidney parameters at last follow-up. However, the duration of follow-up is short in two patients (1.5 and 3.3 years), longer in the other two (11 and 12 years). All had unilateral WT, three underwent unilateral nephrectomy and one had NSS.

Genotype-phenotype correlation of constitutional WT1 pathogenic variant has also been studied in children presenting with steroid-resistant nephrotic syndrome (SRNS), with or without Wilms tumour $[34,35]$. Long-term preservation of kidney function was found in $25.0 \%( \pm 3.5 \%)$ of 61 children at 10 years from diagnosis of SRNS. Truncating pathogenic variants were associated with a later age at onset of SRNS and splice site pathogenic variants with a slower rate of progression to kidney failure [34]. The constitutional WT1 pathogenic variant spectrum overlaps with those described here and in other studies of children who present with Wilms tumour rather than nephrotic syndrome. However, the potential for knowledge of the WT1 pathogenic variant to accurately predict kidney function longevity will require larger numbers of children presenting with cancer or kidney failure to be systematically screened for WT1 pathogenic variant. With the increasing application of genome sequencing in routine diagnostics, such data are likely to be available in the not too distant future [36].

The strength of this study is that we were able to assemble a large cohort of patients with a rare condition treated at a single centre in whom we have detailed genetic and clinical data. The limitations include the retrospective nature of the data collection, the wide range of length of follow-up for kidney outcomes, and the possibility that covariates (e.g. body mass index) could confound the assessment of kidney function.

In conclusion, our study confirms that WT1 pathogenic variant is associated with early age of WT diagnosis, GU malformation, bilateral tumours, stromal histology, and ILNR. However, the presence of rhabdomyoblastic differentiation, albuminuria at diagnosis, and persistent hypertension should also raise suspicion of underlying WT1 pathogenic variant. We would therefore propose that even in the absence of overt clinical features included in the spectrum of WT1 pathogenic variant, the investigation of a germline WT1 pathogenic variant should be considered in the presence of bilateral kidney tumours (which may include any combination of WT or precursor lesion), unilateral multifocal disease, age under 12 months, stromal predominance of the lesion in an infant, and any indication of persistent kidney dysfunction or hypertension. Certainly, investigation should be considered if there is presence of any clinical feature within the spectrum of a WT1 mutation syndrome.

Furthermore, despite the higher frequency of CKD and kidney failure, about two-thirds of the patients in our cohort sustained normal eGFR over a median follow-up period of 9 years. This should guide oncology management regarding the balanced decision about performing NSS without compromising oncological risk. At present, it remains unclear which factors may indicate a higher risk of more rapid deterioration of kidney function. Larger international studies are needed to better categorize these patients according to genotype, phenotype, and the risk of developing kidney failure. Such information would undoubtedly influence decision-making about clinical treatment planning. Since constitutional WT1 pathogenic variant underlying WT is rare, an international study is required to gather data in a consistent prospective fashion.

Abbreviations AN, aniridia; CKD, chronic kidney disease; DDS, Denys-Drash syndrome; DMS, diffuse mesangial sclerosis; eGFR, estimated glomerular filtration rate; GU, genitourinary; GOSH, Great Ormond Street Hospital; ILNR, intralobar nephrogenic rests; NWTS, National Wilms Tumor Study; NR, nephrogenic rests; NSS, nephronsparing surgery; PLNR, perilobar nephrogenic rests; SRNS, steroid-resistant nephrotic syndrome; WAGR, WAGR syndrome; WT, Wilms tumour

Acknowledgements We thank the health professionals who managed the care of these children at Great Ormond Street Hospital for Children NHS Foundation Trust.

Funding This research was supported by the NIHR Great Ormond Street Hospital Biomedical Research Centre. KPJ is funded in part by Great Ormond Street Hospital (GOSH) Children's Charity, Cancer Research UK (Grant No. C1188/ A4614) and Children's Cancer, and Leukaemia Group grants with the Little Princess Trust (CCLGA 2019 10) and Bethany's Wish (CCLGA 2017 02).

\section{Declarations}

Conflict of interest The authors declare no competing interests.

Disclaimer The views expressed are those of the author(s) and not necessarily those of the NHS, the NIHR, or the Department of Health.

Open Access This article is licensed under a Creative Commons Attribution 4.0 International License, which permits use, sharing, adaptation, distribution and reproduction in any medium or format, as long as you give appropriate credit to the original author(s) and the source, provide a link to the Creative Commons licence, and indicate if changes were made. The images or other third party material in this article are included in the article's Creative Commons licence, unless indicated otherwise in a credit line to the material. If material is not included in the article's Creative Commons licence and your intended use is not permitted by statutory regulation or exceeds the permitted use, you will need to obtain permission directly from the copyright holder. To view a copy of this licence, visit http://creativecommons.org/licenses/by/4.0/. 


\section{References}

1. Chu A, Heck JE, Ribeiro KB, Brennan P, Boffetta P, Buffler P, Hung RJ (2010) Wilms' tumour: a systematic review of risk factors and meta-analysis. Paediatr Perinat Epidemiol 24:449-469. https:// doi.org/10.1111/j.1365-3016.2010.01133.x

2. Rivera MN, Haber DA (2005) Wilms' tumour: connecting tumorigenesis and organ development in the kidney. Nat Rev Cancer 5: 699-712. https://doi.org/10.1038/nrc1696

3. Spreafico F, Bellani FF (2006) Wilms' tumor: past, present and (possibly) future. Expert Rev Anticancer Ther 6:249-258. https:// doi.org/10.1586/14737140.6.2.249

4. Stiller CA, Parkin DM (1990) International variations in the incidence of childhood renal tumours. Br J Cancer 62:1026-1030. https://doi.org/10.1038/bjc. 1990.432

5. Breslow NE, Collins AJ, Ritchey ML, Grigoriev YA, Peterson SM, Green DM (2005) End stage renal disease in patients with Wilms tumor: results from the National Wilms Tumor Study Group and the United States Renal Data System. J Urol 174:1972-1975. https://doi.org/10.1097/01.ju.0000176800.00994.3a

6. Diller L, Ghahremani M, Morgan J, Grundy P, Reeves C, Breslow N, Green D, Neuberg D, Pelletier J, Li FP (1998) Constitutional WT1 mutations in Wilms' tumor patients. J Clin Oncol 16:3634 3640. https://doi.org/10.1200/JCO.1998.16.11.3634

7. Scott RH, Stiller CA, Walker L, Rahman N (2006) Syndromes and constitutional chromosomal abnormalities associated with Wilms tumour. J Med Genet 43:705-715. https://doi.org/10.1136/jmg. 2006.041723

8. Breslow NE, Takashima JR, Ritchey ML, Strong LC, Green DM (2000) Renal failure in the Denys-Drash and Wilms' tumor-aniridia syndromes. Cancer Res 60:4030-4032

9. Schumacher V, Scharer K, Wuhl E, Altrogge H, Bonzel KE, Guschmann M et al (1998) Spectrum of early onset nephrotic syndrome associated with WT1 missense mutations. Kidney Int 53: 1594-1600. https://doi.org/10.1046/j.1523-1755.1998.00948.x

10. Koziell AB, Grundy R, Barratt TM, Scambler P (1999) Evidence for the genetic heterogeneity of nephropathic phenotypes associated with Denys-Drash and Frasier syndromes. Am J Hum Genet 64: 1778-1781. https://doi.org/10.1086/302409

11. Little SE, Hanks SP, King-Underwood L, Jones C, Rapley EA et al (2004) Frequency and heritability of WT1 mutations in nonsyndromic Wilms' tumor patients: a UK Children's Cancer Study Group study. J Clin Oncol 22:4140-4146. 10.1200/jco.2004.02.136

12. Schumacher V, Schuhen S, Sonner S, Weirich A, Leuschner I et al (2003) Two molecular subgroups of Wilms' tumors with or without WT1 mutations. Clin Cancer Res 9:2005-2014

13. Lange J, Peterson SM, Takashima JR, Grigoriev Y, Ritchey ML et al (2011) Risk factors for end stage renal disease in non-WT1syndromic Wilms tumor. J Urol 186:378-386. https://doi.org/10. 1016/j.juro.2011.03.110

14. Cozzi DA, Zani A (2006)Nephron-sparing surgery in children with primary renal tumor: indications and results. Semin Pediatr Surg 15: 3-9. https://doi.org/10.1053/j.sempedsurg.2005.11.002

15. Wilde JC, Aronson DC, Sznajder B, Tinteren HV, Powis M et al (2014) Nephron sparing surgery (NSS) for unilateral Wilms tumor (UWT): the SIOP 2001 experience. Pediatr Blood Cancer 61:21752179. https://doi.org/10.1002/pbc.25185

16. Cost NG, Sawicz-Birkowska K, Kajbafzadeh AM, Tourchi A, Parigi GB et al (2014) A comparison of renal function outcomes after nephron-sparing surgery and radical nephrectomy for nonsyndromic unilateral Wilms tumor. Urology 83:1388-1393. https:// doi.org/10.1016/j.urology.2014.01.051

17. Pelletier J, Bruening W, Kashtan CE, Mauer SM, Manivel JC et al (1991) Germline mutations in the Wilms' tumor suppressor gene are associated with abnormal urogenital development in Denys-
Drash syndrome. Cell 67:437-447. https://doi.org/10.1016/00928674(91)90194-4

18. Coppes MJ, Huff V, Pelletier J (1993)Denys-Drash syndrome: relating a clinical disorder to genetic alterations in the tumor suppressor gene WT1. J Pediatr 123:673-678. https://doi.org/10.1016/ S0022-3476(05)80839-X

19. Vujanic GM, Sandstedt B, Harms D, Anna Kelsey A, Ivo Leuschner I et al (2002) Revised International Society of Paediatric Oncology (SIOP) working classification of renal tumors of childhood. Med Pediatr Oncol 38:79-82. https://doi.org/10. 1002/mpo. 1276

20. Selistre L, De Souza V, Cochat P, Ferreira Antonello IC, HadjAissa A et al (2012) GFR estimation in adolescents and young adults. J Am Soc Nephrol 23:989-996. https://doi.org/10.1681/ ASN.2011070705

21. De Souza VC, Rabilloud M, Cochat P, Selistre L, Hadj-Aissa A et al (2012) Schwartz formula: is one k-coefficient adequate for all children? PLoS One 7:e53439. https://doi.org/10.1371/journal. pone. 0053439

22. Levin A, Stevens PE (2014) Summary of KDIGO 2012 CKD guideline: behind the scenes, need for guidance, and a framework for moving forward. Kidney Int 85:49-61. https://doi.org/10.1038/ ki.2013.444

23. Hu M, Craig J, Howard N, Kan A, Chaitow J et al (2004) A novel mutation of WT1 exon 9 in a patient with Denys-Drash syndrome and pyloric stenosis. Pediatr Nephrol 19:1160-1163. https://doi. org/10.1007/s00467-004-1564-3

24. Schumacher V, Schneider S, Figge A, Wildhardt G, Harms D et al (1997) Correlation of germ-line mutations and two-hit inactivation of the WT1 gene with Wilms tumors of stromal-predominant histology. Proc Natl Acad Sci U S A 94:3972-3977. https://doi.org/10. 1073/pnas.94.8.3972

25. Royer-Pokora B, Beier M, Henzler M, Alam R, Schumacher V et al (2004)Twenty-four new cases of WT1 germline mutations and review of the literature: genotype/phenotype correlations for Wilms tumor development. Am J Med Genet A 127A:249-257. https:// doi.org/10.1002/ajmg.a.30015

26. Clarkson PA, Davies HR, Williams DM, Chaudhary R, Hughes IA, Patterson MN (1993) Mutational screening of the Wilms's tumour gene, WT1, in males with genital abnormalities. J Med Genet 30: 767-772. https://doi.org/10.1136/jmg.30.9.767

27. Shibata R, Hashiguchi A, Sakamoto J, Yamada T, Umezawa A, Hata J (2002) Correlation between a specific Wilms tumour suppressor gene (WT1) mutation and the histological findings in Wilms tumour (WT). J Med Genet 39:e83. https://doi.org/10. 1136/jmg.39.12.e83

28. Lee DG, Han DH, Park KH, Baek M (2011) A novel WT1 gene mutation in a patient with Wilms' tumor and 46 , XY gonadal dysgenesis. Eur J Pediatr 170:1079-1082. https://doi.org/10.1007/ s00431-011-1439-0

29. Bruening W, Bardeesy N, Silverman BL, Cohn RA, Machin GA et al (1992) Germline intronic and exonic mutations in the Wilms' tumour gene (WT1) affecting urogenital development. Nat Genet 1: 144-148. https://doi.org/10.1038/ng0592-144

30. Pritchard-Jones K, Fleming S, Davidson D, Bickmore W, Porteous D et al (1990) The candidate Wilms' tumour gene is involved in genitourinary development. Nature 346:194197. https://doi.org/10.1038/346194a0

31. Kreidberg JA, Sariola H, Loring JM, Maeda M, Pelletier J et al (1993)WT-1 is required for early kidney development. Cell 74: 679-691. https://doi.org/10.1016/0092-8674(93)90515-R

32. Mueller RF (1994) The Denys-Drash syndrome. J Med Genet 31: 471-477. https://doi.org/10.1136/jmg.31.6.471

33. Segers H, Kersseboom R, Alders M, Pieters RR, Wagner AA et al (2012) Frequency of WT1 and $11 \mathrm{p} 15$ constitutional aberrations and 
phenotypic correlation in childhood Wilms tumour patients. Eur $\mathrm{J}$ Cancer 48:3249-3256. https://doi.org/10.1016/j.ejca.2012.06.008

34. Lipska BS, Ranchin B, Iatropoulos P, Gellermann J, Melk A et al (2014)Genotype-phenotype associations in WT1 glomerulopathy. Kidney Int 85:1169-1178. https://doi.org/10.1038/ki.2013.519

35. Ahn YH, Park EJ, Kang HG, Kim SH, Cho HY et al (2017)Genotype-phenotype analysis of pediatric patients with WT1 glomerulopathy. Pediatr Nephrol 32:81-89. https://doi.org/ 10.1007/s00467-016-3395-4
36. Genomics England NHS Project (2018) Secretary of State for Health and Social Care announces ambition to sequence 5 million genomes within five years. https://www.genomicsengland.co.uk/ matt-hancock-announces-5-million-genomes-within-five-years/

Publisher's note Springer Nature remains neutral with regard to jurisdictional claims in published maps and institutional affiliations. 